\title{
Earth's Atmosphere Prevailing Surface Winds Based on Effectiveness of Mbane Biouele Formula Derived in 2009
}

\author{
César Mbane Biouele \\ Laboratory of Earth's Atmosphere Physics, Department of Physics, University of Yaoundé I, \\ Yaoundé, Cameroun \\ Email: cesar.mbane@yahoo.fr
}

Received 23 January 2014; revised 20 February 2014; accepted 27 February 2014

Copyright (C) 2014 by author and Scientific Research Publishing Inc.

This work is licensed under the Creative Commons Attribution International License (CC BY). http://creativecommons.org/licenses/by/4.0/

(c) (i) Open Access

\begin{abstract}
Any system designed to simulate the earth's atmosphere general circulation, must necessarily be based on the spatial-or temporal average conditions. Irregularities in the profiles of air motions that we observe on daily weather maps often make lose any real meaning to the general circulation. As complicated and inconsistent that is the daily traffic of air particles, it is interesting to define a general circulation characteristic of the average air transportation around the globe. Indeed, this transport responds to a need to transfer heat from the equator (heat source) to the poles (cold sources). Mbane Biouele formula (2009), derived from Clausius-Clapeyron relation (1832), now allows faithful and unique representation of the tricellular general circulation: Hence, the possibility of access to the earth's atmosphere prevailing surface winds in summer as well as winter.
\end{abstract}

\section{Keywords}

Earth's Atmosphere General Circulation; Daily Traffic of Air Particles; Heat Transfer from the Equator to the Poles; Prevailing Surface Winds

\section{Introduction}

As complicated and inconsistent that is the daily traffic of atmosphere's air particles, it is interesting to define a general circulation characteristic of the average air transportation around the globe. Indeed, this transport responds to a need to transfer heat from the equator (heat source) to the poles (cold sources). Given the fact that atmospheric or climate phenomena are usually a combination of elementary events whose scales range from the 
very small (microscopic) to the infinity large (synoptic), general circulation should be understood as a synoptic scale phenomenon and thus be built from the spatial and temporal average. e.g. earth's surface must be regarded as homogeneous, flat and uniform and ground's temperature as a monotonically decreasing function from the meteorological equator(ITCZ in this case) to the south and north poles. If the earth's surface temperature average is calculated for one year, we find that the entire region of the earth between latitudes $30^{\circ}$ to $35^{\circ}$ North and South is characterized by a radiant energy gain while regions at higher latitudes accuse a net deficit. Heat Transport from the equator to the poles is necessary otherwise the temperature would be very high at the equator and very low at the poles. This flow of heat from the equator to the poles can only be convective type (that is to say, accompanied by mass transport), other transfer modes (conduction and radiation) are completely negligible for horizontal heat transport (due to weak horizontal temperature gradient, poor conductivity of soils, etc.). Environments that are likely to accommodate mass transit are: oceans on the one hand, atmosphere on the other. By an unprecedented luck, the formula found by Mbane [1]-[5] now allows faithful and unique representation of the tricellular general circulation. Hence, the possibility of access to the earth's atmosphere prevailing surface winds in summer as well as winter.

\section{Mbane Biouele Formula on the Troposphere Dynamic Balance}

\subsection{Atmosphere Dynamics Concept of Air Particle}

Atmosphere Dynamics use a set of assumptions (previously uncontested) to define the particle or parcel of air [6]-[8]. Especially:

1) Few exchanges on molecular scale: it is easy to follow quantity of air which preserves certain properties.

2) Quasi-static equilibrium: at any moment there is dynamic balance, i.e., the particle has the same pressure as its environment $\left(P=P_{\text {ext }}\right)$.

3) No thermal balance: heat transfers by conduction are very slow and neglected. One can have $T \neq T_{\text {ext }}$.

4) The horizontal sizes of the air particle can go from a few $\mathrm{cm}$ to $100 \mathrm{~km}$ according to the applications.

\subsection{Mbane Biouele Formula on the Troposphere Dynamic Balance}

Taking into account the fact that the atmosphere is mainly composed of dry air and water vapor, the Dalton's law connects the pressure $(P)$ with the partial pressure of dry air $\left(P_{a}\right)$ and saturated water vapor $\left(e_{w}\right)$

$$
P=P_{a}+e_{w}
$$

In deriving $(P)$ with respect to the temperature, one has

$$
\frac{\mathrm{d} P}{\mathrm{~d} T}=\left(\frac{\partial P}{\partial T}\right)_{V}+\left(\frac{\partial P}{\partial V}\right)_{T}\left(\frac{\mathrm{d} V}{\mathrm{~d} T}\right)
$$

According to the Quasi-static equilibrium (or dynamic balance) the pressure of the parcel of air must be the same as that of the ambient air, including during sudden local changes in phases by water contained in this parcel. Reality that all meteorologists restore through the following famous sentence: the phases change takes place at constant pressure. Thereby write Equation (3),

$$
\mathrm{d} P=0
$$

Equations (2) and (3) lead to the derivative of $V$ compared to $T$

$$
\frac{\mathrm{d} V}{\mathrm{~d} T}=-\frac{\left(\frac{\partial P}{\partial T}\right)_{V}}{\left(\frac{\partial P}{\partial V}\right)_{T}}
$$

Introducing the coefficient of thermal expansion of moist air at constant temperature

$$
\chi=-\frac{1}{P}\left(\frac{\partial P}{\partial V}\right)_{T}
$$

Then the Fundamental Relationship of Atmosphere Dynamic Balance: 


$$
\frac{\mathrm{d} V}{\mathrm{~d} T}=\frac{1}{\chi} \cdot \frac{1}{P}\left(\frac{\partial P}{\partial T}\right)_{V}
$$

One can also write equation of Atmosphere dynamic balance in terms of partial pressures

$$
\frac{\mathrm{d} V}{\mathrm{~d} T}=\frac{1}{\chi} \cdot \frac{1}{P}\left[\left(\frac{\partial P_{a}}{\partial T}\right)_{V}+\left(\frac{\partial e_{\mathrm{w}}}{\partial T}\right)_{V}\right]
$$

$\left(\frac{\partial P_{a}}{\partial T}\right)_{V}$ is negligible compared to $\left(\frac{\partial e_{w}}{\partial T}\right)_{V}$

Thereby write Formula (8) named Mbane Biouele formula on troposphere dynamic balance

$$
\frac{\mathrm{d} V}{\mathrm{~d} T} \cong \frac{1}{\chi} \cdot \frac{1}{P}\left[\left(\frac{\partial e_{\mathrm{w}}}{\partial T}\right)_{V}\right]
$$

Formula (8) leads to a meteorological very useful statement:

At any moment and throughout the atmosphere, one can use Formula (8) and Clausius-Clapeyron slope of the equilibrium curves in the eT-diagram (Figure 1) to predict in which direction the air parcel will move (up or down) if its temperature increases or decreases. Table 1 or Figure 2 provides an overview of possible situations throughout the Troposphere.

\section{Appropriate and Unique Representation of Earth's Atmosphere General Circulation}

According to our previous study [9], the presence of water substance in all three states in the earth's atmosphere gives to troposphere the exclusivity of a general circulation consists of three groups of passive convective cells (Hadley, Ferrel, and Polar) on either side of the ITCZ (Inter Tropical Convergence Zone). These cells (H, F, and P) take place within areas bounded by both tropopause and the two equal level surfaces of water vapor and temperature rating respectively at $6.11 \mathrm{mb}$ and $0.0098^{\circ} \mathrm{C}$ as suggested in Figure 3 .

\section{Appropriate Representations of Earth's Atmosphere Prevailing Surface Winds}

Everyone agrees with physical law which shows that Coriolis force acts to the right in the northern hemisphere (to the left in the southern hemisphere). Therefore, Hadley, Ferrel and Polar cells trigger due to earth's rotation effects: easterly (or westerly) winds depending on location where these cells are observed. Prevailing surface winds that result are distributed as suggested by the Figures 4-6. Figure 4(a) and Figure 4(b) suggest the profiles of prevailing surface winds during the summer (with respect to the northern hemisphere). Figure 5(a) and Figure 5(b) suggest the profiles of prevailing surface winds when the ITCZ is aligned with the geographic equator. Figure 6(a) and Figure 6(b) suggest the profiles of prevailing surface winds during the winter (with respect to the northern hemisphere). The eT-diagram coordinates $\left(6.11 \mathrm{mb}\right.$ and $\left.\mathbf{0 . 0 0 9 8}^{\circ} \mathbf{C}\right)$ of water triple-point allow each of us to easily locate Polar front and Horse latitude respectively. The general circulation plots provided by Figure 4(a) and Figure (6a) clearly show that: prevailing winds (easterlies or westerlies) at $500 \mathrm{hPa}$ levels (levels commonly used in meteorology as reference) can be totally different with ground surface prevailing winds. Unfortunately meteorologists confused all the time, prevailing winds at $500 \mathrm{hPa}$ with those on the ground surface. e.g., In January the TV meteorological presenters see the arrival of tropical warm air masses on Europe. In fact, this is exactly cold tropical air masses that descend along the $0.0098^{\circ} \mathrm{C}$ isotherm Figure 6(a) and contribute to the installation of winter in Europe. i.e., Ferrel and Hadley cells carry (through isothermal compression) cold air masses from tropical mid-troposphere to European low-troposphere (Figure 6(a)). This misinterpretation is due to the fact that the general circulation was long remained poorly drawn and contradictions like this one would be completely avoided when our appropriate and faithful plots of the general circulation will be delivered to a very wide audience.

\section{Conclusions}

It is now proven that between the two equal level surfaces of temperature and water vapors rating respectively at 


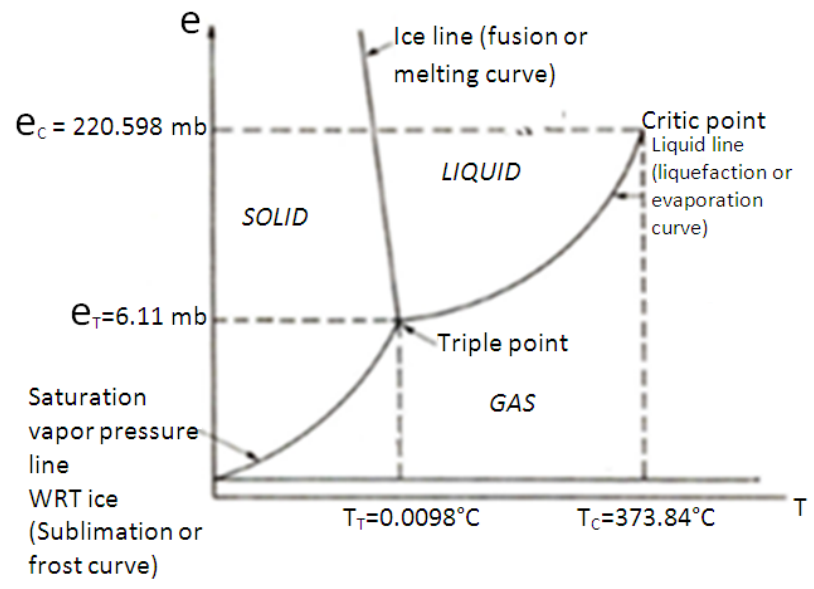

Figure 1. Saturation curves for water substance onto the eTplane $\left(e_{w T}\right.$ and $T_{T}$ are triple-point coordinates): $e_{w T}=6.11 \mathrm{mb}$; $T_{T}=0.0098^{\circ} \mathrm{C}$.

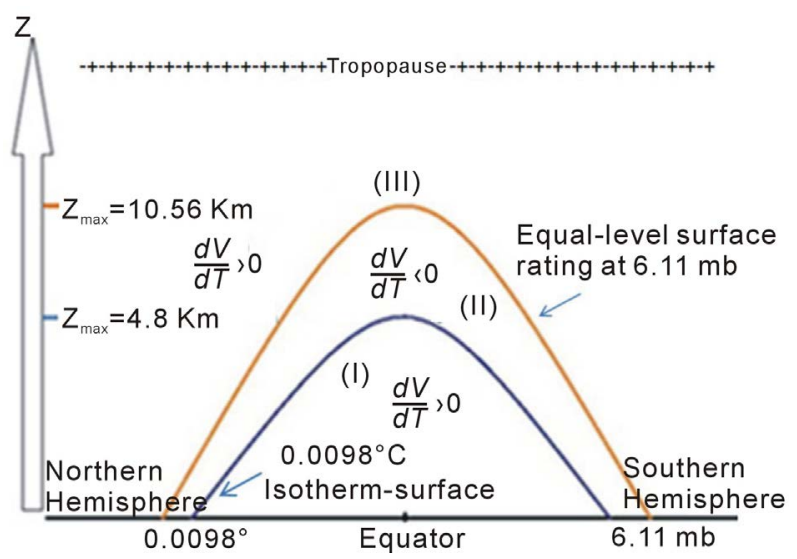

Figure 2. Troposphere specific regions depending on the manner in which $V$ changes with $T$ ( $V$ and $T$ are respectively volume and temperature of an air parcel): If $(\mathrm{d} V / \mathrm{d} T)>0$ the particle swells when its temperature increases (so it becomes lighter), if $(\mathrm{d} V / \mathrm{d} T)<0$ the particle shrinks when its temperature increases (so it becomes less light). $Z_{\max }$ are statistical value of observed maximum elevation of equal level surfaces of temperature and water vapor rating respectively at $0.0098^{\circ} \mathrm{C}$ and $6.11 \times 10^{-3}$ bars.

Table 1. Changes in volume of the moist air particle depending on temperature within a specific range of temperature and humidity.

\begin{tabular}{cccc}
\hline $\begin{array}{c}\text { Range of Temperature coupled } \\
\text { with Range of humidity }\end{array}$ & $\begin{array}{c}\boldsymbol{T}<\mathbf{0 . 0 0 9 8}^{\circ} \mathbf{C} \\
\boldsymbol{e}_{w}<\mathbf{6 . 1 1} \mathbf{~ m b}\end{array}$ & $\begin{array}{c}\boldsymbol{T}<\mathbf{0 . 0 0 9 8} \mathbf{C}^{\circ} \mathbf{C} \\
\boldsymbol{e}_{w}>\mathbf{6 . 1 1} \mathbf{~ m b}\end{array}$ & $\begin{array}{c}\boldsymbol{T}>\mathbf{0 . 0 0 9 8} \mathbf{C}^{\circ} \mathbf{C} \\
\boldsymbol{e}_{w}>\mathbf{6 . 1 1}_{\mathbf{~ m b}}\end{array}$ \\
\hline$\left(\frac{\partial e_{\mathrm{w}}}{\partial T}\right)_{V}$ & + & - & + \\
$\frac{\mathrm{d} V}{\mathrm{~d} T}$ & + & - & + \\
\hline
\end{tabular}

$0.0098^{\circ} \mathrm{C}$ and $6.11 \mathrm{mb}$, troposphere thermoelastic properties are diametrically opposed to those of the ideal gas. The consequences of this revelation on our perception of climate phenomena are many. For instance, hot air is not always lighter than cold air throughout the troposphere. This thermodynamic property was unfortunately 


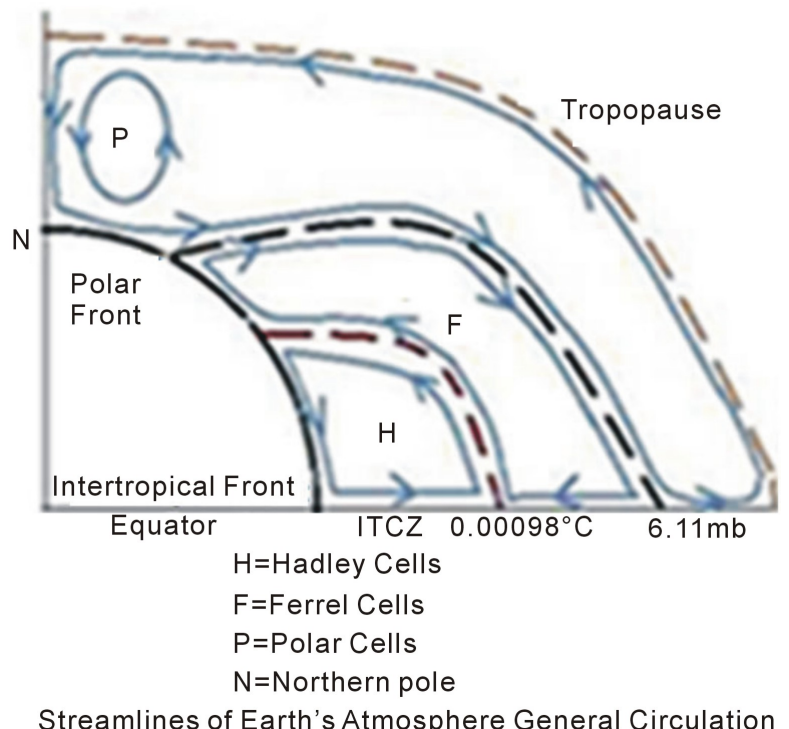

Figure 3. Schematic representation of the general circulation, derived from Mbane Biouele formula (2009) and related corollaries.

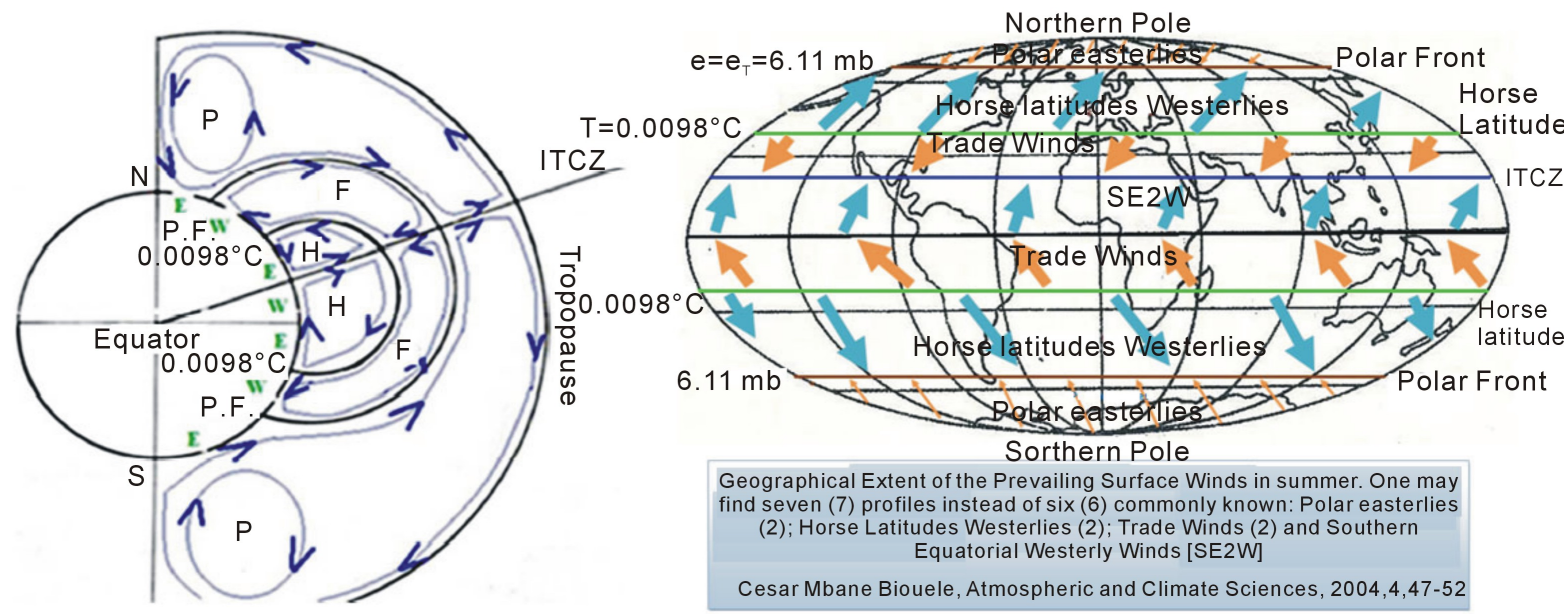

(a)

(b)

Figure 4. (a) Schematic localization of prevailing surface winds in summer: with respect to northern hemisphere; (b) Worldwide geographical extent of the prevailing surface winds in summer: with respect to northern hemisphere.

unknown to public and has led to numerous errors and inconsistencies that abound in many Atmospheric and Climate Sciences publications (including audiovisuals productions). Before using perfect gas assumption everyone must now remember that one of the constituents of the atmosphere (saturated water vapor in this case) has, depending on the location, behavior diametrically opposite to that of ideal gas. This subtle precaution allows avoiding misinterpretations like that updrafts are necessarily associated with warming or that downdrafts are necessarily associated with cooling. Clausius-Clapeyron formula (1832) combined with Carnot principle (1824) strengthens our knowledge of the passive convection movements (throughout the troposphere) and finally allows earth's atmosphere tricellular circulation thermodynamics and kinematics. Each of us will now easily remember that the presence of water substance in all three states in the earth's atmosphere gives to troposphere the exclusivity of a general circulation consists of three groups of passive convection cells (Hadley-Ferrel and Polar). The results presented in this work, demonstrate effectiveness of Mbane Biouele formula (2009) and attract the attention of each other on the importance of general circulation and related prevailing surface winds. Our works (past 


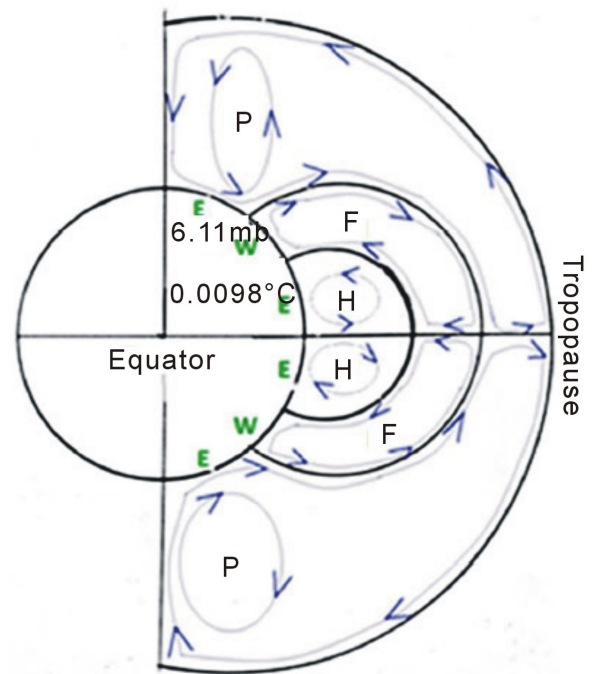

(a)

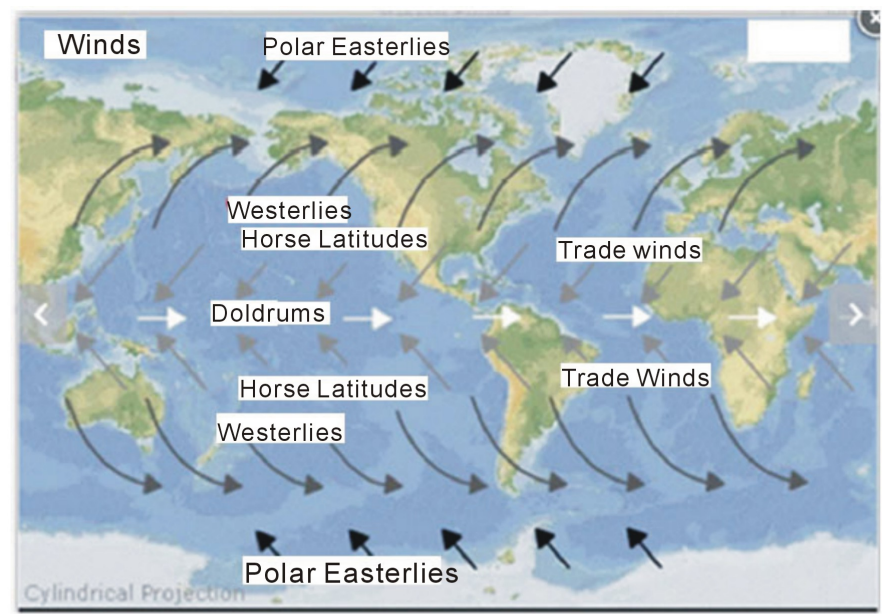

Geographical distribution of surface prevailing winds when the ITCZ (white darts) coincides with the equator

(b)

Figure 5. (a) Schematic localization of prevailing surface winds ( $E=$ Easterlies, $W=$ Westerlies) when the ITCZ is positioning along the equator; (b) Worldwide geographical extent of the prevailing surface winds when the ITCZ is positioning along the equator.

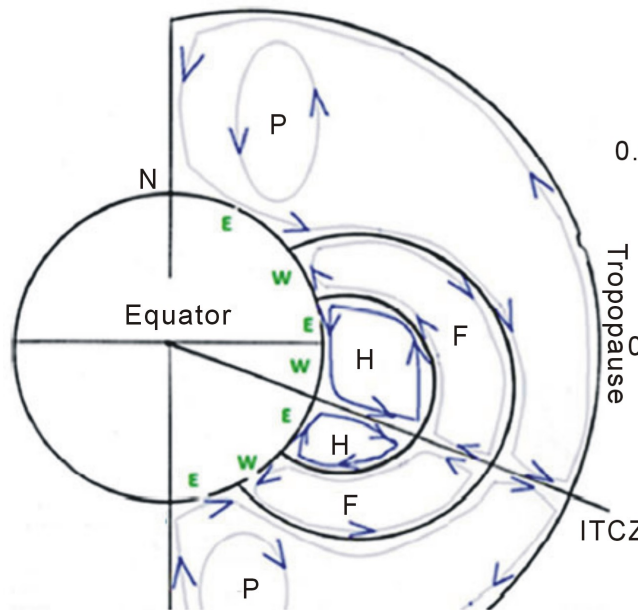

(a)

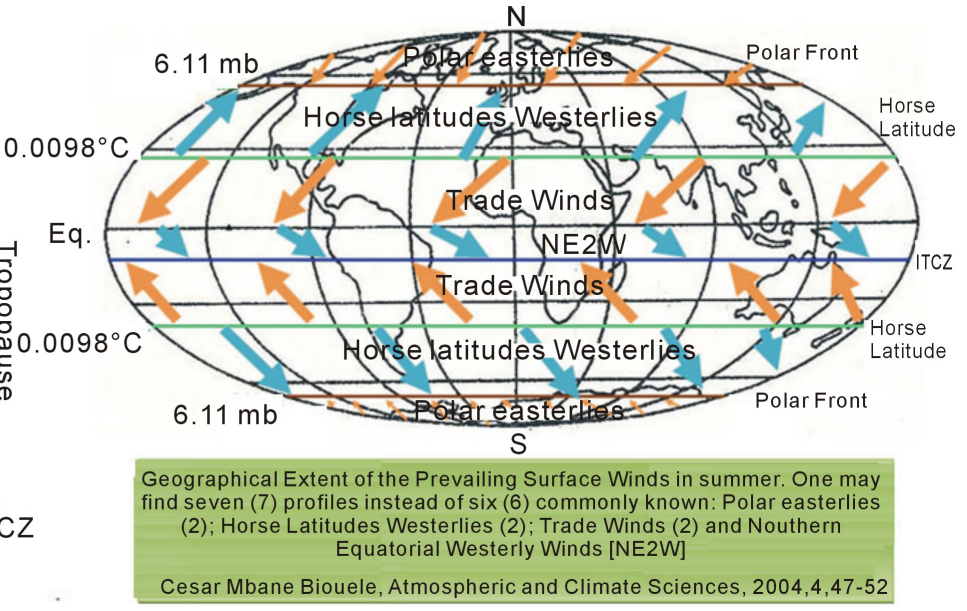

(b)

Figure 6. (a) Schematic localization of prevailing surface winds in winter: with respect to northern hemisphere; (b) Worldwide geographical extent of the prevailing surface winds in winter: with respect to northern hemisphere.

and present) offer the following views:

1) The origin of electric charges and the events that result (thunderclouds and related lightning) are well known today.

2) Now everyone knows how the volume of the particle of air varies when its temperature increases or decreases, in any part of the atmosphere. Vertical movement results can be easily predicted.

3) Everyone can now distinguish perfectly warm depression (Hurricanes) compared to cold depression (e.g., Cyclones).

4) It is now possible for all of us to seek ways of preventing the extent of damage caused by the tropical depression.

5) We can predict obvious consequence of global warming: The occurrence of tropical storms will be more frequent and many more areas are affected, including those which were spared (e.g., floods affecting many cities in France and Italy in January 2014): it is important to know that high temperatures trigger high evapotranspi- 
ration and related clouds. For causing fall of $1^{\text {st }}$ Hadley cell's clouds coming from tropical regions (i.e. very big rainfalls), natural "contamination" of these clouds made of liquid particles, is required and is easily performed above developed towns by carbon dioxide which abound in that area. Cement covers a large part of the area occupied by modern cities and prevents infiltration: that transforms modern cities in pools that run-off water fills easily.

6) Airline pilots will now be better informed on vertical profiles of hurricanes or cyclones (e.g.: vertical and horizontal profiles of winds, vertical distribution of electrical charges and profiles of electric fields) triggered by warm or cold disturbances respectively.

7) Tropical depressions fuel is water vapor and they are subject to the Coriolis force that deviates systematically these disturbances to the west, both in the northern than in the southern hemisphere. The prevailing winds triggered by the general circulation inhibit or promote this movement.

\section{References}

[1] Couanang Siebatcheu, B., Mbane Biouele, C. and Eyebe Fouda, J.S. (2012) Atmosphere Dynamic Balance Model (ADB-Model) and Related Troposphere General Circulations' Cells behind the Formation of Tropical Monsoons. Scholars Research Library-Archives of Physics Research, 3, 93-100.

[2] Mbane Biouele, C. (2013) Hurricanes and Cyclones Kinematics and Thermodynamics Based on Clausius-Clapeyron Relation Derived in 1832. International Journal of Physical Sciences, 8, 1284-1290.

[3] Mbane Biouele, C., Yizengaw, E., Moldwin, M.B. and Cautenet, G. (2011) Impacts of Thermoelastic Properties of Saturated Water Vapor on Tropical Depressions Thermodynamics and Dynamics. Scholars Research Library-Archives of Physics Research, 2, 24-33.

[4] Mbane Biouele, C. (2009) Vertical Profiles of Winds and Electric Fields Triggered by Tropical Storms-Under the Hydrodynamic Concept of Air Particle. International Journal of Physical Sciences, 4, 242-246.

[5] Mbane Biouele, C. (2012) Physics of Atmosphere Dynamic or Electric Balance Processes Such as Thunderclouds and Related Lighting Flashes. Geosciences, 2, 6-10. http://dx.doi.org/10.5923/j.geo.20120201.02

[6] Byers, H.R. (1959) General Meteorology. McGraw-Hill Book Company, Inc., New York, 540 p.

[7] Batchelor, G.K. (1967) An Introduction to Fluid Dynamics. Cambridge University Press, Cambridge, 496 p.

[8] Riegel, C.A. (1992) Fundamentals of Atmospheric Dynamics and Thermodynamics. World Scientific Publishing Co. Pte. Ltd., Singapore, 512 p.

[9] Mbane Biouele, C. (2014) Application of Clausius-Clapeyron Relation (1832) and Carnot Principle (1824) to Earth's Atmosphere Tricellular Circulation. Atmospheric and Climate Sciences, 4, 1-6. http://dx.doi.org/10.4236/acs.2014.41001 